\title{
RESEARCH ARTICLE \\ Activation of the immune defence of the freshwater snail Lymnaea stagnalis by different immune elicitors
}

\author{
Otto Seppälä ${ }^{1,2, *}$ and Katja Leicht ${ }^{1,3}$ \\ ${ }^{1}$ Eawag, Swiss Federal Institute of Aquatic Science and Technology, 8600 Dübendorf, Switzerland, ${ }^{2} E T H$ Zürich, \\ Institute of Integrative Biology, 8092 Zürich, Switzerland and ${ }^{3}$ Department of Biological and Environmental Science, \\ 40014 University of Jyväskylä, Finland \\ *Author for correspondence (otto.seppaelae@eawag.ch)
}

\begin{abstract}
SUMMARY
Understanding the outcomes of host-parasite interactions in nature is in high demand as parasites and pathogens are important for several ecological and evolutionary processes. Ecological immunology (ecoimmunology) has a key role in reaching this goal because immune defence is the main physiological barrier against infections. To date, ecoimmunological studies largely lean on measuring constitutive immune defences (components of defence that are always active). However, understanding the role of inducible components of immune function is important as the immune system is largely an inducible defence. Measuring such defences can be complicated as different parasites may activate different immune cascades, and expression of different immune traits may not be independent. We examined the suitability of different immune activation techniques for the freshwater snail Lymnaea stagnalis. By experimentally challenging snails with different immune elicitors [injection with snail saline (i.e. wounding), lyophilized Escherichia coli cells, lyophilized Micrococcus lysodeikticus cells, healthy snail gonad, and trematodeinfected snail gonad; maintenance in microorganism-enriched water] and measuring phenoloxidase-like and antibacterial activity of their haemolymph, we found increased immune activity against some immune elicitors, but also decreased activity. Our findings suggest potentially complicated relationships among immune traits, and propose suitable techniques for ecological studies in this study system.
\end{abstract}

Key words: immune function, immunocompetence, ecological immunology, ecoimmunology, phenoloxidase activity, antibacterial activity.

Received 3 January 2013; Accepted 8 March 2013

\section{INTRODUCTION}

Current ecological and evolutionary biological research shows wide interest in host-parasite interactions because parasites and pathogens are ubiquitous and fundamentally important for both ecological and evolutionary processes (reviewed by Hatcher and Dunn, 2011; Schmid-Hempel, 2011). In understanding these processes, ecological immunology [or ecoimmunology (Demas and Nelson, 2012)] has a key role as immune defence is the main physiological barrier against infections (reviewed by Janeway et al., 2005). In fact, ecoimmunological studies have proven to be very useful in understanding the outcomes of host-parasite interactions and thus disease dynamics by linking the host physiology and ecological factors affecting susceptibility in a natural context.

The majority of ecoimmunological studies have focused on measuring constitutive defences, in other words, the components of immune function that are always active (Janeway et al., 2005). However, the immune system is largely an inducible defence system; after recognising 'non-self' agents, different immune cascades are activated, leading to production of immunological effectors that eliminate and/or control invaders (Janeway et al., 2005). Therefore, understanding the role of inducible components of immune function in host-parasite ecology is in high demand. Measuring inducible defences, however, requires the use of proper immune activation techniques. In many systems, effective methods for activating host immune function have been developed (see Moret and SchmidHempel, 2000; Råberg and Stjernman, 2003; Rantala et al., 2000;
Saino et al., 1997). In many others, however, results of activations are difficult to interpret, leading to a high number of ecologically relevant studies remaining unpublished. These problems could be at least partly due to the lack of knowledge of the effects of various immune elicitors on different immune cascades, and the relationships among immune traits in their expression.

In this study, we examined the suitability of different immune activation techniques for ecoimmunological research in the freshwater snail Lymnaea stagnalis (L.). We compared the activation of two commonly measured immune parameters of snail haemolymph [phenoloxidase (PO)-like activity and antibacterial activity (see Seppälä and Jokela, 2010; Seppälä and Jokela, 2011)] after exposing snails to different immune elicitors. We expected variation in the effects of immune elicitors because of potentially specific immune responses. Our results showed increased levels of immune defence against some immune elicitors in the examined immune parameters, but also reduced activity in some cases. These results suggest potentially complicated relationships among immune cascades in L. stagnalis and highlight the importance of thorough pre-testing as well as careful interpretation of results in ecoimmunological studies using immune activation.

\section{MATERIALS AND METHODS}

Study system and experimental animals

Lymnaea stagnalis is a holarctic freshwater snail inhabiting shallow littoral zones of stagnant waters such as lakes and ponds. It is an 
important host for a community of parasites including several highly virulent trematode species (Väyrynen et al., 2000) that castrate the snails and increase their mortality (e.g. Karvonen et al., 2004). Lymnaea stagnalis is currently used in ecoimmunological studies examining context dependence of snail immune function [e.g. effects of resource availability (Seppälä and Jokela, 2010) and ambient temperature (Seppälä and Jokela, 2011)], as well as interactions among genetic and environmental factors in determining immune function (Seppälä and Jokela, 2010). Previous work in this system has, however, mainly focused on constitutive defences, and techniques to investigate inducible defences have not been well developed. Experimental snails used in the present study came from a laboratory stock population ( $\mathrm{F}_{2}$ generation) originating from a pond in Dättnau, Switzerland $\left(47^{\circ} 29^{\prime} \mathrm{N}, 8^{\circ} 41^{\prime} \mathrm{E}\right)$.

\section{Experiment 1: injections with immune elicitors}

In the first experiment, we randomly assigned snails (shell length $27.3-42.0 \mathrm{~mm}$ ) into six different treatment groups (15 individuals per treatment; there was no difference in the size of the snails in different treatments; ANOVA: $\left.F_{5,84}=1.566, P=0.179\right)$. In all groups, we anaesthetized the snails by placing them into $2 \%$ diethyl ether for $2 \mathrm{~min}$. After that, we treated each snail according to its treatment group. In the first group, we did not expose snails to any immune elicitor after anaesthesia, and used them as non-exposed controls. In the second group, we injected $100 \mu \mathrm{l}$ of snail saline (see Standen, 1975) into the side of the foot of each snail using a syringe $\left(0.24 \mathrm{~mm} \times 16 \mathrm{~mm}\right.$ Microlane $^{\mathrm{TM}} 3, \mathrm{BD}$, Franklin Lakes, NJ, USA). This treatment examined the effect of wounding in activating immune defence when compared with uninjected snails (see above), and also served as a control group for the treatments involving injections of immune elicitors into the snail tissues (see below). In the third and the fourth groups, we injected each snail as above using lyophilized Escherichia coli (Sigma-Aldrich, Steinheim, Germany) and Micrococcus lysodeikticus (synonym Micrococcus luteus; Sigma-Aldrich) cells $\left(0.5 \mathrm{mg} \mathrm{ml}^{-1}\right.$ in snail saline), respectively. We chose to use both a gram-negative $(E$. coli) and a gram-positive ( $M$. lysodeikticus) bacterium as they could differ in their effect on activation of snail immune function [lipopolysaccharides of gram-negative bacteria and peptidoglycans of gram-positive bacteria are recognized by the host immune system (Montminy et al., 2006; Poltorak et al., 1998; Takehana et al., 2002)]. In the fifth and sixth groups, we injected each snail with healthy and Plagiorchis sp. (Trematoda)-infected gonad tissue [a mixture from two other snail individuals per treatment that originated from a pond in Winterthur, Switzerland $\left.\left(47^{\circ} 28^{\prime} \mathrm{N}, 8^{\circ} 43^{\prime} \mathrm{E}\right)\right]$, respectively. We dissected these snails and crushed the gonads of each of them in a $1.5 \mathrm{ml}$ tube using a plastic pestle. We diluted $100 \mu$ of the crushed tissue (i.e. healthy gonad or a mixture of gonad and parasite sporocysts) into $1 \mathrm{ml}$ of snail saline, vortexed the mixture and centrifuged it briefly. We collected the supernatant and used that in injections. After injections, we placed the snails individually into plastic cups filled with 0.21 of aged tap water $\left(20^{\circ} \mathrm{C}\right)$ and fed them with fresh lettuce ad libitum.

Six hours after the injections, we sampled snail haemolymph to estimate the immunocompetence of target snails. We removed the snails from their containers, blotted them dry and collected haemolymph samples by gently tapping the foot of each snail to induce the expulsion of blood (Sminia, 1981). We collected samples to measure the PO-like and antibacterial activity of snail haemolymph. PO is a component of oxidative defences employed mainly against eukaryotic pathogens (see Cerenius and Söderhäll, 2004), whereas humoral antimicrobial proteins are used to resist microbial infections (see Imler and Bulet, 2005). Both of them are important components of immune defence in invertebrates including molluscs (e.g. Allam et al., 2006; Bahgat et al., 2002; Butt and Raftos, 2008; Hellio et al., 2007; Hernroth, 2003; Mitta et al., 2000; Muñoz et al., 2006). We snap-froze the haemolymph samples in liquid nitrogen $[10 \mu \mathrm{l}$ of haemolymph mixed with $100 \mu \mathrm{l}$ of phosphate buffered saline (PBS; $\mathrm{pH} 7.4$ ) for PO activity assay, and $70 \mu \mathrm{l}$ of pure haemolymph for antibacterial activity assay], and stored them at $-80^{\circ} \mathrm{C}$.

At a later date, we thawed the stored haemolymph samples on ice and measured their PO-like and antibacterial activity. In the PO assay, we placed $40 \mu \mathrm{l}$ of a sample into a 96 -well microtiter plate well containing $140 \mu \mathrm{l}$ of ice-cold water and $20 \mu \mathrm{l}$ of ice-cold PBS. After that, we added $20 \mu$ of ice-cold L-DOPA (Sigma-Aldrich) solution $\left(4 \mathrm{mg} \mathrm{ml}^{-1}\right.$ in $\left.\mathrm{H}_{2} \mathrm{O}\right)$ into the well and allowed the reaction to proceed at $30^{\circ} \mathrm{C}$. In the reaction, L-DOPA is oxidized, which leads to an increase in the absorbance of the solution. We measured the absorbance at $480 \mathrm{~nm}$ using a microtiter plate reader (Infinite 200, Tecan, Salzburg, Austria) immediately after adding the LDOPA and again after $6 \mathrm{~h}$. In addition, we measured four nonhaemolymph controls (haemolymph replaced with water) per microtiter plate to control for non-enzymatic oxidation of L-DOPA. We then calculated the PO-like activity as differences in absorbance between the measurement times (absorbance after $6 \mathrm{~h}-$ absorbance at time 0 ; the mean change in non-haemolymph controls was subtracted from the data). We recorded the change in absorbance as milliunits. Note that the used method measured the amount of active PO in snail haemolymph, not the amount of zymogenic proPO (see Cerenius and Söderhäll, 2004).

In the antibacterial activity assay, we measured the antibacterial activity of snail haemolymph against lyophilized $E$. coli cells. We placed $50 \mu \mathrm{l}$ of a sample into a 96-well microtiter plate well and mixed it with $200 \mu \mathrm{l}$ of $E$. coli solution $\left(0.35 \mathrm{mg} \mathrm{m}^{-1}\right.$ in sodium phosphate buffer; $\mathrm{pH} 6.0)$ at $20^{\circ} \mathrm{C}$. In the reaction, antimicrobial enzymes destroy bacterial cells, which leads to a decrease in the absorbance of the solution. We measured the absorbance at $450 \mathrm{~nm}$ using a microtiter plate reader (Infinite 200) immediately after mixing the haemolymph and bacteria and again after $30 \mathrm{~min}$. In addition, we measured four non-haemolymph controls (haemolymph replaced with water) per microtiter plate to control for changes in absorbance caused by factors other than antibacterial activity of haemolymph. We then calculated the antibacterial activity as differences in absorbance between the measurement times (absorbance at time 0 - absorbance after $30 \mathrm{~min}$; the mean change in non-haemolymph controls was subtracted from the data). We recorded the change in absorbance as milliunits.

\section{Experiment 2: exposure to opportunistic microorganisms}

In the second experiment, we randomly assigned snails (shell length $27.6-48.2 \mathrm{~mm}$ ) into two different water quality (clean and microorganism-enriched) and exposure time (6h and 2 days) treatments (15 individuals per treatment combination; there was no difference in the size of the snails in different treatment groups; ANOVA: water quality, $F_{1,56}=1.172, P=0.284$; exposure time, $F_{1,56}=1.298, P=0.256$; water quality $\times$ exposure time, $F_{1,56}=0.224$, $P=0.638)$. The aim of the water quality treatment was to manipulate snail immune activity by predisposing snails to a community of opportunistic microorganisms that grow in water (see Moret et al., 2010). These microorganisms invade the snails as a part of normal exchange between snail haemolymph and the surrounding water, which challenges their immune function (Rigby and Jokela, 2000). To prepare microorganism-enriched water, we aged a solution of 
lysogeny broth medium $\left[2 \mathrm{mll}^{-1}\right.$ in $\mathrm{H}_{2} \mathrm{O}$; tryptone (Sigma-Aldrich) $10 \mathrm{mg} \mathrm{ml}^{-1}, \mathrm{NaCl}$ (Sigma-Aldrich) $10 \mathrm{mg} \mathrm{ml}^{-1}$, yeast extract (SigmaAldrich) $5 \mathrm{mg} \mathrm{ml}^{-1}$, algae medium $\left[1 \mathrm{mll}^{-1}\right.$ in $\mathrm{H}_{2} \mathrm{O} ; \mathrm{KNO}_{3}$ (Merck, Darmstadt, Germany) $10.1 \mathrm{mg} \mathrm{ml}^{-1}, \mathrm{KH}_{2} \mathrm{PO}_{4}$ (Sigma-Aldrich) $0.1 \mathrm{mg} \mathrm{ml}^{-1}, \mathrm{MgSO}_{4}$ (Sigma-Aldrich) $1.1 \mathrm{mg} \mathrm{m}^{-1}$ ] and sugar $\left(1.5 \mathrm{gl}^{-1}\right.$ in $\mathrm{H}_{2} \mathrm{O}$ ) for 5 days. Before use, we made a 1:3 dilution in aged tap water. We placed the snails individually into plastic cups filled with 0.21 of water according to their treatment $\left(20^{\circ} \mathrm{C}\right)$ and fed them with fresh lettuce ad libitum. We changed the water for snails maintained for 2 days after 1 day. After exposures, we took the haemolymph samples and measured the immune parameters as described above. We could not measure PO-like activity from one snail and excluded it from further analysis.

\section{Statistical analyses}

To examine the effects of experimental treatments on snail immune defence in Experiment 1, we first analysed the variation in snail immune function using a multivariate analysis of variance (MANOVA). In this analysis, we used PO-like activity and antibacterial activity of snail haemolymph as response variables, and experimental treatment [no injection, injection with snail saline (i.e. wounding), injection with $E$. coli, injection with $M$. lysodeikticus, injection with healthy gonad, injection with trematodeinfected gonad] as a fixed factor. We log-transformed PO-like activity to fulfil the assumptions of MANOVA. We also analysed the data using a model that included the shell length of the snails as a covariate, but as the covariate was not statistically significant we did not use it in the final model. After this, we analysed the variation in each response variable separately using ANOVAs with similar models as above complemented with contrasts to examine whether the observed effects were similar across different immune parameters. We used specific contrasts to compare each treatment group with its control group (i.e. injection with snail saline versus no injection; injections with immune elicitors versus injection with snail saline). We also estimated the potential phenotypic trade-off between PO-like and antibacterial activity of snail haemolymph. To do this we examined the relationship between the parameters at an individual level by correlating the residuals of the variables from the above ANOVA models using a Pearson's correlation. This way we were able to control for the effects of experimental treatments.

To examine the effects of experimental treatments on snail immune defence in Experiment 2, we first analysed the variation in snail immune function using a MANOVA. In this analysis, we used POlike activity and antibacterial activity of snail haemolymph as response variables, and water quality (clean, microorganism-enriched) and exposure time (6h, 2 days) as fixed factors. We included the interaction between the factors into the model. We also analysed the data using a model that included the shell length of the snails as a covariate, but as the covariate was not statistically significant we did not use it in the final model. After this, we analysed the variation in each response variable separately using ANOVAs with similar models as above to examine whether the observed effects were similar across different immune parameters. We also estimated the relationship between POlike and antibacterial activity of snail haemolymph at an individual level as above. We performed all statistical analyses using SPSS 19.0 software (IBM, Armonk, NY, USA).

\section{RESULTS}

Experiment 1: injections with immune elicitors

In general, the level of snail immune activity varied across different treatments (MANOVA: Pillai's trace $=0.440, \quad F_{10,168}=4.734$, $P<0.001$; Fig. 1). Both PO-like and antibacterial activity of snail
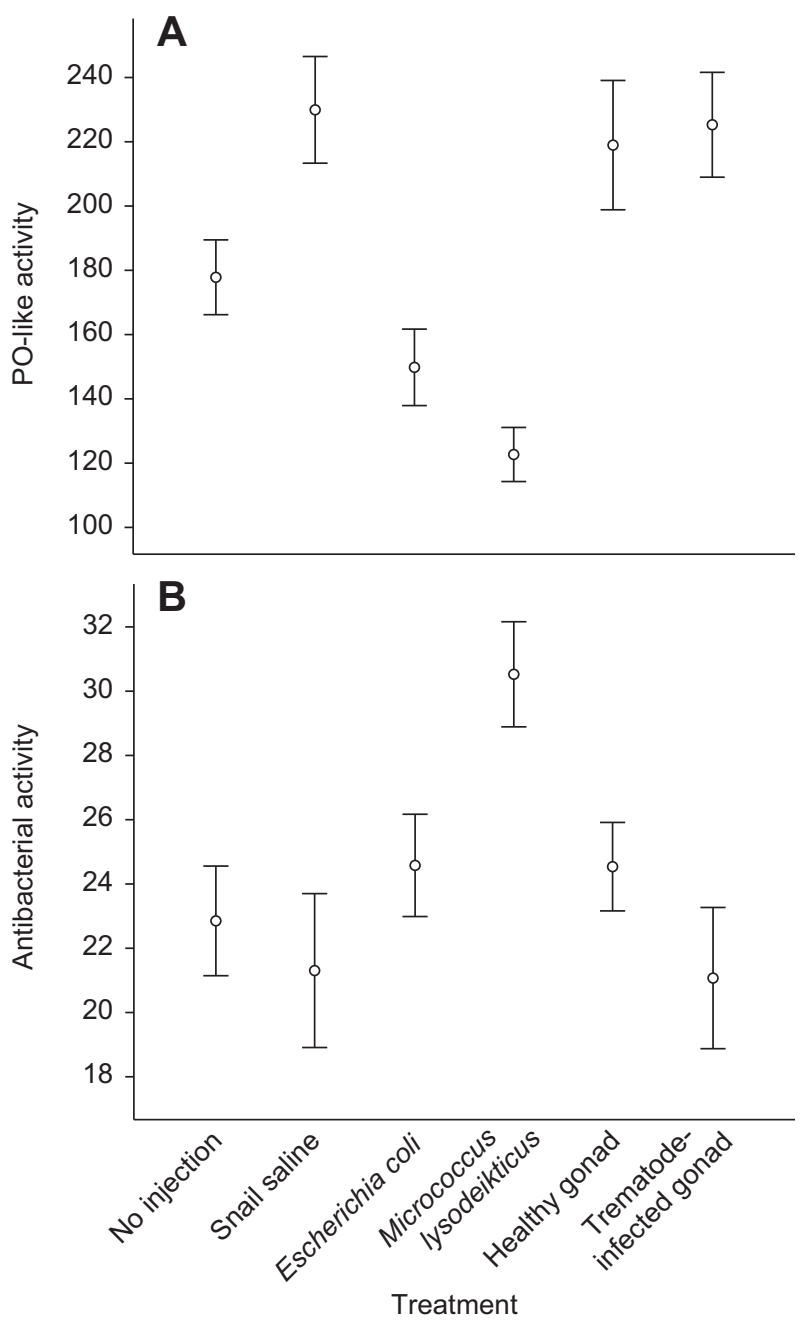

Fig. 1. (A) Phenoloxidase (PO)-like activity (milliunits; mean \pm s.e.m.) and (B) antibacterial activity (milliunits; mean \pm s.e.m.) of haemolymph in Lymnaea stagnalis snails injected with different immune elicitors $(6 \mathrm{~h}$ post exposure).

haemolymph differed among treatment groups (ANOVAs: PO-like activity: $F_{5,84}=10.023, P<0.001$; antibacterial activity: $F_{5,84}=3.513$, $P=0.006$ ), but the observed effects differed between the measured immune parameters. Wounding (i.e. injection with snail saline) increased the PO-like activity of snail haemolymph compared with the snails that did not receive any injection (contrast estimate $=0.252$, $P=0.027$; Fig. 1A). Injections with any of the used immune elicitors did not lead to further increase in PO-like activity. The level of POlike activity in snails injected with $E$. coli and M. lysodeikticus cells was decreased compared with the snails injected with snail saline (E. coli: contrast estimate $=0.431, P<0.001 ; M$. lysodeikticus: contrast estimate $=0.623, P<0.001$; Fig. $1 \mathrm{~A}$ ), and the snails injected with healthy and trematode-infected gonad tissue did not show any responses (healthy gonad: contrast estimate $=0.083, P=0.470$; trematode-infected gonad: contrast estimate $=0.023, P=0.844$; Fig. 1A). Wounding did not affect the antibacterial activity of snail haemolymph compared with the snails that did not receive any injection (contrast estimate $=1.547, P=0.556$; Fig. 1B). Injection with $M$. lysodeikticus cells increased the level of antibacterial activity compared with the snails injected with snail saline (contrast estimate $=9.220, P=0.001$; Fig. $1 \mathrm{~B}$ ), but the snails injected with other 

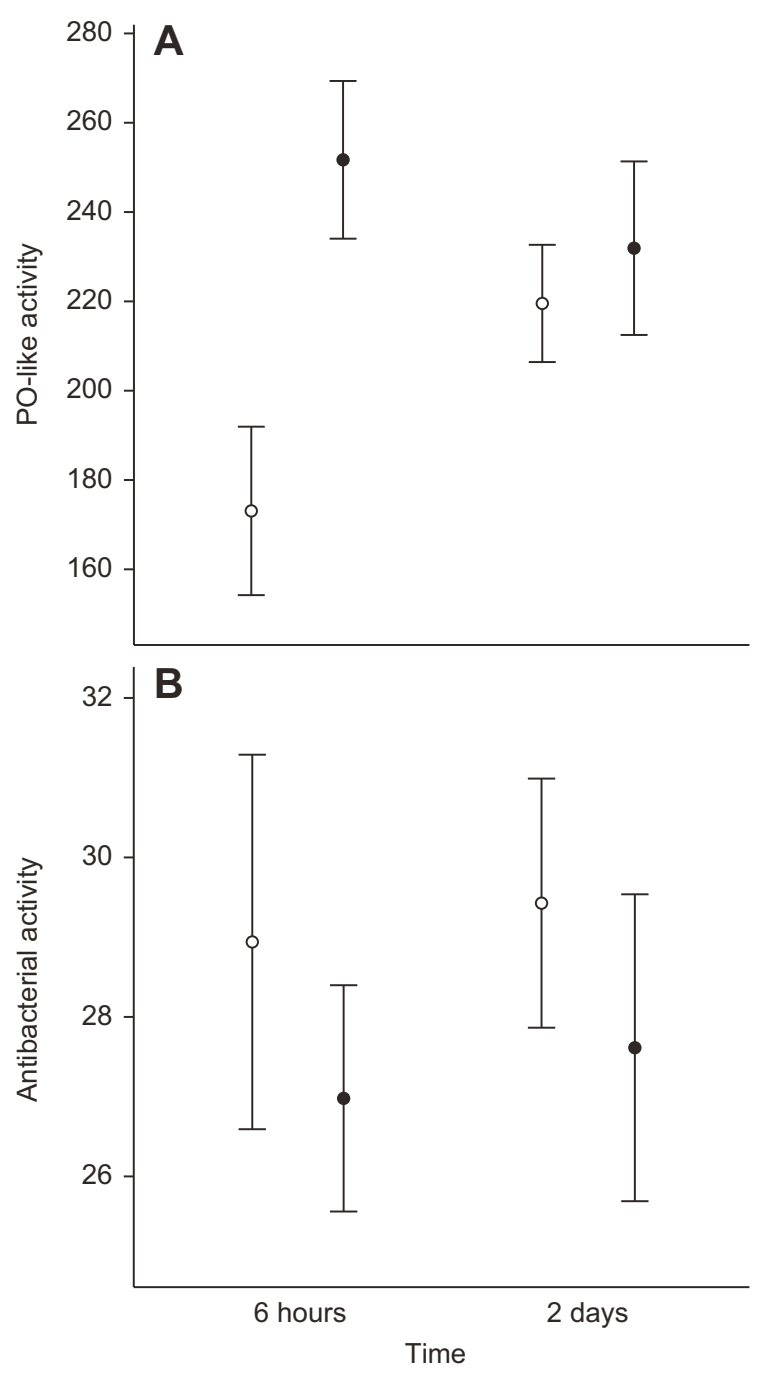

Fig. 2. (A) Phenoloxidase (PO)-like activity (milliunits; mean \pm s.e.m.) and (B) antibacterial activity (milliunits; mean \pm s.e.m.) of haemolymph in Lymnaea stagnalis snails maintained in different water quality treatments (clean, open circles; microorganism-enriched, filled circles) for different times (6h, 2 days).

immune elicitors did not show any responses (E. coli: contrast estimate $=3.273, P=0.222$; healthy gonad: contrast estimate $=3.233$, $P=0.228$; trematode-infected gonad: contrast estimate $=0.233$, $P=0.930$; Fig. 1B). At the individual level, when controlling for the effects of experimental treatments, PO-like and antibacterial activity of snail haemolymph were negatively correlated $(r=-0.237$, $P=0.025)$.
Experiment 2: exposure to opportunistic microorganisms In general, the level of snail immune activity varied across different water quality treatments (MANOVA: Pillai's trace $=0.122$, $F_{2,54}=3.760, P=0.030$; Fig. 2 ). Exposure time did not significantly affect immune function (MANOVA: main effect, Pillai's trace $=0.012, F_{2,54}=0.339, P=0.714$; water quality $\times$ exposure time, Pillai's trace $\left.=0.061, F_{2,54}=1.768, P=0.180\right)$. The above effects, however, differed between the measured immune parameters (Table 1, Fig. 2). The level of PO-like activity in snails maintained in microorganism-enriched water was higher compared with the snails maintained in clean water (Table 1, Fig. 2A). Furthermore, the difference in PO-like activity between water quality treatments showed a tendency towards being higher after $6 \mathrm{~h}$ maintenance compared with 2 days maintenance (Fig. 2A), which was indicated by the interaction term between water quality and exposure time that was close to statistically significant (Table 1). Neither water quality nor exposure time affected antibacterial activity of snail haemolymph (Table 1, Fig. 2B). PO-like and antibacterial activity of snail haemolymph were not correlated at the individual level $(r=0.032, P=0.810)$.

\section{DISCUSSION}

Current research in ecological immunology largely leans on studies measuring constitutive immune defences. However, the understanding of the role of inducible components of immune function in host-parasite ecology and evolution is also in high demand. Measuring such defences can be complicated as different parasites and immune elicitors may activate different immune cascades (Janeway et al., 2005), and furthermore, expression of different immune traits may not be independent (Cotter et al., 2004). In this study, we examined the suitability of different immune activation techniques for the freshwater snail L. stagnalis. By experimentally challenging snails with different immune elicitors [injection with snail saline (i.e. wounding), lyophilized E. coli cells, lyophilized $M$. lysodeikticus cells, healthy snail gonad, and trematode-infected snail gonad; maintenance in microorganismenriched water] and measuring PO-like and antibacterial activity of their haemolymph, we found increased immune activity against some immune elicitors, but also decreased activity in some cases. Our findings suggest potentially complicated relationships among immune traits, and we propose suitable techniques for further ecological studies in this study system.

In Experiment 1 (injections with immune elicitors), wounding (i.e. injection with snail saline) increased the PO-like, but not the antibacterial, activity of snail haemolymph compared with uninjected controls. Increased PO-like activity in this treatment is likely to be related to wound healing rather than immune defence as snails were not exposed to any immune elicitors and PO has been reported to be involved not only in immune function but also in wound healing

Table 1. ANOVAs for the PO-like and antibacterial activity of snail haemolymph by water quality (clean, microorganism-enriched) and exposure time (6h, 2 days)

\begin{tabular}{|c|c|c|c|c|c|}
\hline & Source & d.f. & MS & $F$ & $P$ \\
\hline \multirow[t]{4}{*}{ PO-like activity } & Water quality & 1 & $30,503.197$ & 6.795 & 0.012 \\
\hline & Time & 1 & 2621.566 & 0.584 & 0.448 \\
\hline & Water quality $\times$ Time & 1 & $16,167.677$ & 3.602 & 0.063 \\
\hline & Error & 55 & 4488.932 & & \\
\hline \multirow[t]{4}{*}{ Antibacterial activity } & Water quality & 1 & 52.496 & 1.026 & 0.316 \\
\hline & Time & 1 & 4.633 & 0.091 & 0.765 \\
\hline & Water quality $\times$ Time & 1 & 0.081 & 0.002 & 0.968 \\
\hline & Error & 55 & 51.174 & & \\
\hline
\end{tabular}


in insects (Bidla et al., 2005; Galko and Krasnow, 2004; Lai et al., 2002).

Interestingly, injections with bacterial (E. coli and $M$. lysodeikticus) cells led to reduced PO-like activity of snail haemolymph compared with the snails injected with snail saline. This result could take place via two different mechanisms. First, the level of PO-like activity might be reduced if PO is used more rapidly for defence than it is generated. Second, PO-like activity can be downregulated if bacterial injections activate other immune traits which are traded-off with PO-like activity. Increased antibacterial activity was actually observed against injection with M. lysodeikticus cells. This, as well as the negative relationship between PO-like and antibacterial activity of snail haemolymph at the individual level (a phenotypic trade-off), suggests that reduced PO-like activity may be at least partly due to downregulation when other immune traits are activated. However, although injection with M. lysodeikticus cells increased antibacterial activity of snail haemolymph, a similar effect was not observed following an injection with $E$. coli cells. This is surprising because antibacterial activity of haemolymph was tested against $E$. coli. It is possible, however, that injection with $E$. coli cells activates antibacterial defence, but this could not be observed if defence proteins were used to clear bacterial cells with the same speed as they were generated. Alternatively, dynamics of an immune response could differ depending on the bacterial challenge, leading to different activity of immune parameters at the same time point (van der Knaap et al., 1981). Furthermore, activation of antibacterial defence against E. coli by $M$. lysodeikticus cells is possible as activation of different immune cascades can be correlated [i.e. defences against both bacteria are activated following an exposure to only one of them (see Imler and Bulet, 2005)].

Injections with healthy and trematode-infected gonad tissue collected from other snail individuals did not affect PO-like or antibacterial activity of snail haemolymph when compared with the snails injected with snail saline. The lack of responses in the group of snails injected with trematode-infected gonad tissue is unexpected because a strong immune response could be assumed against trematode parasites as they are highly virulent (e.g. Karvonen et al., 2004 ) and also common in natural snail populations (Väyrynen et al., 2000; Voutilainen et al., 2009). However, it is possible that responses are simply not seen in the parameters measured in this experiment if some other defence mechanisms are used against them. Potential candidates for such mechanisms are, for example, reactive oxygen species such as hydrogen peroxide (Bayne, 2009) and lectins such as fibrinogen-related proteins (reviewed by Loker, 2010), which have been reported to be important in snail defences against trematodes in other species. Furthermore, trematodes are known to be able to effectively avoid and supress snail immune function (reviewed by Loker, 2010), which could also explain the lack of increased immune activity in this study.

In Experiment 2 (exposure to opportunistic microorganisms), maintenance in microorganism-enriched water increased immune activity of snail haemolymph. This effect, however, was only observed in PO-like activity. The lack of response in antibacterial defence is surprising as microorganism-enriched water can be expected to include several different bacteria that could activate snail defences when the microorganisms enter the snails (Rigby and Jokela, 2000). However, it is possible that activation was not observed if the response was very fast (see van der Knaap et al., 1981) or if defence proteins were used with the same speed as they were generated. The effect of microorganism-enriched water on POlike activity of snail haemolymph was clearer after $6 \mathrm{~h}$ exposure compared with the snails maintained in different water quality treatments for 2 days. This was because the antibacterial activity of snail haemolymph was at a higher level in individuals maintained in the clean water for 2 days than in the snails maintained in the same treatment for $6 \mathrm{~h}$. This could be because water quality may also decrease in the clean water treatment when the maintenance time lengthens (i.e. microorganisms start to grow). Contrary to Experiment 1, evidence for a phenotypic trade-off between the examined immune parameters at an individual level was not observed in this experiment. This suggests that such a trade-off may not be strong in our study system and calls for further studies examining its generality.

To conclude, our results showed wide variation in the effects of different immune elicitors on immune activity of snail haemolymph. Furthermore, our findings indicate potentially complicated relationships between different immune cascades as some immune elicitors increased the level of one of the examined immune parameters but did not have an effect on or even reduced the activity of others. In our study system, maintenance in microorganismenriched water seems a suitable method for activating snail immune defence as it increased PO-like activity of snail haemolymph, and is also an easy method to use in large-scale ecological studies. However, use of microorganism-enriched water may not be suitable for experimental designs in which environmental factors potentially affecting growth rate and community structure of microbes (e.g. temperature) are manipulated. In L. stagnalis, injections with immune elicitors can also be useful, but their use needs to be planned based on which immune parameters are in focus in each specific study. This is because none of the examined immune elicitors increased both PO-like and antibacterial activity of snail haemolymph. This highlights also the importance for thorough pretesting as well as careful interpretation of results in ecoimmunological studies using immune activations in other study systems.

\section{ACKNOWLEDGEMENTS}

We thank J. Jokela and anonymous reviewers for their helpful comments on the manuscript.

\section{AUTHOR CONTRIBUTIONS}

O.S. and K.L. designed and conducted the study. O.S. analysed the data and wrote the first draft of the manuscript. K.L. provided comments on the manuscript.

\section{COMPETING INTERESTS}

No competing interests declared.

\section{FUNDING}

This study was supported by the Emil Aaltonen Foundation and the Swiss National Science Foundation.

\section{REFERENCES}

Allam, B., Paillard, C., Auffret, M. and Ford, S. E. (2006). Effects of the pathogenic Vibrio tapetis on defence factors of susceptible and non-susceptible bivalve species: II. Cellular and biochemical changes following in vivo challenge. Fish Shellfish Immunol. 20, 384-397.

Bahgat, M., Doenhoff, M., Kirschfink, M. and Ruppel, A. (2002). Serine protease and phenoloxidase activities in hemocytes of Biomphalaria glabrata snails with varying susceptibility to infection with the parasite Schistosoma mansoni. Parasitol. Res. 88, 489-494.

Bayne, C. J. (2009). Successful parasitism of vector snail Biomphalaria glabrata by the human blood fluke (trematode) Schistosoma mansoni: a 2009 assessment. Mol. Biochem. Parasitol. 165, 8-18.

Bidla, G., Lindgren, M., Theopold, U. and Dushay, M. S. (2005). Hemolymph coagulation and phenoloxidase in Drosophila larvae. Dev. Comp. Immunol. 29, 669679.

Butt, D. and Raftos, D. (2008). Phenoloxidase-associated cellular defence in the Sydney rock oyster, Saccostrea glomerata, provides resistance against $Q X$ disease infections. Dev. Comp. Immunol. 32, 299-306. 
Cerenius, L. and Söderhäll, K. (2004). The prophenoloxidase-activating system in invertebrates. Immunol. Rev. 198, 116-126.

Cotter, S. C., Kruuk, L. E. B. and Wilson, K. (2004). Costs of resistance: genetic correlations and potential trade-offs in an insect immune system. J. Evol. Biol. 17, 421-429.

Demas, G. E. and Nelson, R. J. (2012). Ecoimmunology. New York, NY: Oxford University Press.

Galko, M. J. and Krasnow, M. A. (2004). Cellular and genetic analysis of wound healing in Drosophila larvae. PLoS Biol. 2, E239.

Hatcher, M. J. and Dunn, A. M. (2011). Parasites in Ecological Communities From Interactions To Ecosystems. Cambridge: Cambridge University Press.

Hellio, C., Bado-Nilles, A., Gagnaire, B., Renault, T. and Thomas-Guyon, H. (2007). Demonstration of a true phenoloxidase activity and activation of a ProPO cascade in Pacific oyster, Crassostrea gigas (Thunberg) in vitro. Fish Shellfish Immunol. 22, 433-440.

Hernroth, B. (2003). The influence of temperature and dose on antibacterial peptide response against lipopolysaccharide in the blue mussel, Mytilus edulis. Fish Shellfis Immunol. 14, 25-37.

Imler, J. L. and Bulet, P. (2005). Antimicrobial peptides in Drosophila: structures, activities and gene regulation. Chem. Immunol. Allergy 86, 1-21.

Janeway, C. A., Travers, P., Walport, M. and Shlomchik, M. (2005). Immunobiology: The Immune System in Health And Disease. New York, NY: Garland Science.

Karvonen, A., Kirsi, S., Hudson, P. J. and Valtonen, E. T. (2004). Patterns of cercarial production from Diplostomum spathaceum: terminal investment or bet hedging? Parasitology 129, 87-92.

Lai, S. C., Chen, C. C. and Hou, R. F. (2002). Immunolocalization of prophenoloxidase in the process of wound healing in the mosquito Armigeres subalbatus (Diptera: Culicidae). J. Med. Entomol. 39, 266-274.

Loker, E. S. (2010). Gastropod immunobiology. Adv. Exp. Med. Biol. 708, 17-43.

Mitta, G., Vandenbulcke, F. and Roch, P. (2000). Original involvement of antimicrobial peptides in mussel innate immunity. FEBS Lett. 486, 185-190.

Montminy, S. W., Khan, N., McGrath, S., Walkowicz, M. J., Sharp, F., Conlon, J. E., Fukase, K., Kusumoto, S., Sweet, C., Miyake, K. et al. (2006). Virulence factors of Yersinia pestis are overcome by a strong lipopolysaccharide response. Nat. Immunol. 7, 1066-1073.

Moret, Y. and Schmid-Hempel, P. (2000). Survival for immunity: the price of immune system activation for bumblebee workers. Science 290, 1166-1168.

Moret, Y., Rigaud, T., Motreuil, S., Troussard, J. P. and Moreau, J. (2010) Condition-dependent ecdysis and immunocompetence in the amphipod crustacean, Gammarus pulex. Biol. Lett. 6, 788-791.

Muñoz, P., Meseguer, J. and Esteban, M. A. (2006). Phenoloxidase activity in three commercial bivalve species. Changes due to natural infestation with Perkinsus atlanticus. Fish Shellfish Immunol. 20, 12-19.
Poltorak, A., He, X. L., Smirnova, I., Liu, M. Y., Van Huffel, C., Du, X., Birdwell, D. Alejos, E., Silva, M., Galanos, C. et al. (1998). Defective LPS signaling in C3H/HeJ and C57BL/10ScCr mice: mutations in TIr4 gene. Science 282, 2085-2088.

Råberg, L. and Stjernman, M. (2003). Natural selection on immune responsiveness in blue tits Parus caeruleus. Evolution 57, 1670-1678.

Rantala, M. J., Koskimäki, J., Taskinen, J., Tynkkynen, K. and Suhonen, J. (2000). Immunocompetence, developmental stability and wingspot size in the damselfly Calopteryx splendens L. Proc. R. Soc. B 267, 2453-2457.

Rigby, M. C. and Jokela, J. (2000). Predator avoidance and immune defence: costs and trade-offs in snails. Proc. R. Soc. B 267, 171-176.

Saino, N., Bolzern, A. M. and Møller, A. P. (1997). Immunocompetence, ornamentation, and viability of male barn swallows (Hirundo rustica). Proc. Natl. Acad. Sci. USA 94, 549-552.

Schmid-Hempel, P. (2011). Evolutionary Parasitology: the Integrated Study of Infections, Immunology, Ecology And Genetics. New York, NY: Oxford University Press.

Seppälä, O. and Jokela, J. (2010). Maintenance of genetic variation in immune defense of a freshwater snail: role of environmental heterogeneity. Evolution 64 2397-2407.

Seppälä, O. and Jokela, J. (2011). Immune defence under extreme ambient temperature. Biol. Lett. 7, 119-122.

Sminia, T. (1981). Gastropods. In Invertebrate Blood Cells (ed. N. A. Ratcliff and A. F. Rowley), pp. 191-232. London: Academic Press.

Standen, N. B. (1975). Voltage-clamp studies of the calcium inward current in an identified snail neurone: comparison with the sodium inward current. J. Physiol. 249 253-268.

Takehana, A., Katsuyama, T., Yano, T., Oshima, Y., Takada, H., Aigaki, T. and Kurata, S. (2002). Overexpression of a pattern-recognition receptor, peptidoglycanrecognition protein-LE, activates imd/relish-mediated antibacterial defense and the prophenoloxidase cascade in Drosophila larvae. Proc. Natl. Acad. Sci. USA 99 13705-13710.

van der Knaap, W. P. W., Sminia, T., Kroese, F. G. M. and Dikkeboom, R. (1981). Elimination of bacteria from the circulation of the pond snail Lymnaea stagnalis. Dev. Comp. Immunol. 5, 21-32.

Väyrynen, T., Siddall, R., Valtonen, E. T. and Taskinen, J. (2000). Patterns of trematode parasitism in lymnaeid snails from northern and central Finland. Ann. Zool. Fenn. 37, 189-199.

Voutilainen, A., van Ooik, T., Puurtinen, M., Kortet, R. and Taskinen, J. (2009). Relationship between prevalence of trematode parasite Diplostomum $\mathrm{sp}$. and population density of its snail host Lymnaea stagnalis in lakes and ponds in Finland. Aquat. Ecol. 43, 351-357. 